\title{
Caracterização florística e fitossociológica do componente arbustivo- arbóreo de uma floresta paludosa no Município de Rio Claro (SP), Brasil ${ }^{1}$
}

\author{
ALOYSIO DE PÁDUA TEIXEIRA² e MARCO A. ASSIS ${ }^{2,3}$
}

(recebido: 6 de maio de 2004; aceito: 7 de abril de 2005)

\begin{abstract}
Floristic and phytosociological characterization of the arboreal and shruby stratum of a swamp forest in Rio Claro (SP), Brazil). The flora and structure of a swamp forest occurring in a declivity in the municipality of Rio Claro, SP, was characterized in order to compare its floristic composition with other swamp forests in the countryside of São Paulo state. The trees $(\mathrm{CBH} \geq 15 \mathrm{~cm})$ were censused in 45 plots of $10 \mathrm{~m} \times 10 \mathrm{~m}(0.45 \mathrm{ha})$. A total of 1,651 living plants in 49 species and 30 families were found. The diversity index $\left(\mathrm{H}^{\prime}\right)$ for species was 2.10 nats.individual ${ }^{-1}$, whereas the equability $(\mathrm{J})$ was 0.54 . The most important species (IV) were Euterpe edulis Mart., Calophyllum brasiliense Cambess., Talauma ovata A. St.-Hill., Cedrela odorata L., Dendropanax cuneatum Decne \& Planch., and Protium spruceanum (Benth.) Engl. The high number of species found in this study can be related with different flooding intensities through the declivity, whereas the low floristic diversity was associated with a high relative density of few species, e.g. E. edulis (41\%). The floristic comparison between swamp forests showed that: i) Calophyllum brasiliense, Cedrela odorata, Dendropanax cuneatum, Protium almecega, Styrax pohlii A. DC., Talauma ovata, and Tapirira guianensis Aubl. compose an important group of dominating species that determine a structural resemblance between the swamp forests in the countryside of São Paulo state; ii) the flora of these forests is very variable, with a large number of exclusive species in only one forest. The results indicates that each fragment of swamp forest besides being very important for occurrence of the populations associated to hidromorphic soils and presents floristic peculiarities that altogether, in a high scale, improve the great diversity.
\end{abstract}

Key words - floristic, phytosociology, swamp forest, tropical forest

RESUMO - (Caracterização florística e fitossociológica do componente arbustivo-arbóreo de uma floresta paludosa no Município de Rio Claro (SP), Brasil). As florestas paludosas ocupam geralmente porções planas de várzeas e fundos de vale. Caracterizou-se a flora e a estrutura de uma floresta paludosa estabelecida sobre um declive acentuado no Município de Rio Claro, SP, visando à comparação florística dessa floresta com outras florestas paludosas estudadas no interior do Estado de São Paulo. Os indivíduos (PAP $\geq 15 \mathrm{~cm}$ ) foram amostrados em 45 parcelas de $10 \mathrm{~m} \times 10 \mathrm{~m}(0,45 \mathrm{ha})$. Foram encontrados 1.651 indivíduos vivos, pertencentes a 49 espécies e 30 famílias. O índice de diversidade (H') para as espécies foi de 2,10 nats.indivíduo-1 e a eqüabilidade (J) foi de 0,54. As espécies mais importantes (em VI) foram Euterpe edulis Mart., Calophyllum brasiliense Cambess., Talauma ovata A. St.-Hill., Cedrela odorata L., Dendropanax cuneatum Decne \& Planch. e Protium spruceanum (Benth.) Engl. O elevado número de espécies, em comparação com as outras florestas, pode ser atribuído aos diferentes períodos de saturação hídrica determinados pelo desnível topográfico, enquanto a baixa diversidade florística é consequiência da elevada densidade relativa de poucas espécies, como Euterpe edulis (41\%). A comparação florística indicou que: i) Calophyllum brasiliense, Cedrela odorata, Dendropanax cuneatum, Protium almecega, Styrax pohlii A. DC., Talauma ovata e Tapirira guianensis Aubl. constituem um importante grupo de espécies que predominam nas florestas paludosas do interior paulista e conferem uma semelhança estrutural a essas formações; ii) a flora dessas florestas mostra-se bastante variada, com muitas espécies exclusivas verificadas em cada estudo. Os resultados sugerem que cada fragmento de floresta paludosa, além de favorecer a ocorrência das principais populações associadas a solos hidromórficos, apresenta peculiaridades florísticas que, somadas, promovem o aumento da diversidade de espécies.

Palavras chave - fitossociologia, floresta higrófila, floresta paludosa, florística

\section{Introdução}

Florestas paludosas, também denominadas de florestas latifoliadas higrófilas ou matas de brejo, são

1. Parte da dissertação de mestrado do primeiro autor.

2. Universidade Estadual Paulista, Instituto de Biociências, Departamento de Botânica, Caixa Postal 199, 13506-900 Rio Claro, SP, Brasil.

3. Autor para correspondência: massis@ rc.unesp.br florestas estabelecidas sobre solos hidromórficos, com presença quase permanente de água na superfície do solo em função do afloramento do lençol freático (Torres et al. 1994, Ivanauskas et al. 1997). Pela ocorrência restrita às áreas de solo encharcado, encontram-se naturalmente fragmentadas, constituindo florestas perenifólias (Leitão Filho 1982), com peculiaridades florísticas e estruturais, diferenciando-se de outras formações que também estão presentes no entorno de 
cursos d'água, mas fora da condição de solo encharcado por longos períodos, como as florestas ripárias e estacionais semidecíduas (Torres et al. 1994, Toniato et al. 1998).

As florestas paludosas sofreram intenso processo de devastação e estão desaparecendo sem que se conheça sua importância para a preservação de recursos hídricos e seus aspectos ecológicos (Torres et al. 1994). A ocupação agrícola das várzeas e a construção de usinas hidrelétricas (Ivanauskas et al. 1997), além de outros fatores de degradação, como fogo e expansão imobiliária, contribuem para a redução dessas florestas tão peculiares e pouco estudadas no Brasil.

Estudos específicos de florestas paludosas, principalmente no Estado de São Paulo, têm se intensificado nos últimos anos e propiciado um considerável aumento do conhecimento dessa formação, através dos relatos de Torres et al. (1994), Costa et al. (1997), Ivanauskas et al. (1997), Toniato et al. (1998), Paschoal \& Cavassan (1999) e Marques et al. (2003), sobretudo quanto à composição florística e à estrutura da comunidade. Nesses estudos ficam evidentes as menores riqueza e diversidade de espécies dessa formação em comparação com outras formações ribeirinhas menos suscetíveis ao encharcamento do solo, a heterogeneidade florística entre fragmentos e a similaridade estrutural em função da prevalência de algumas poucas espécies, usualmente comuns aos diversos remanescentes.

No presente estudo levantou-se a composição da flora e a estrutura fitossociológica do componente arbustivo-arbóreo de uma floresta paludosa localizada no Município de Rio Claro - SP, visando a análise comparativa da composição florística e estrutural deste estudo com outras florestas paludosas estudadas no interior do Estado de São Paulo. Tendo em vista que o fragmento florestal estudado ocupa um trecho de declividade acentuada, situação que o diferencia dos demais remanescentes até então estudados, e que essa situação lhe confere maior heterogeneidade espacial com relação aos padrões de drenagem e encharcamento hídrico do solo, foram investigadas as seguintes questões: i) a formação estudada mostra-se semelhante às demais florestas paludosas, caracterizadas pelo predomínio estrutural de poucas espécies? Em caso afirmativo, seriam as espécies prevalentes comuns aos outros remanescentes? ii) a composição florística repete os níveis de dissimilaridade em comparação com os demais estudos?

\section{Material e métodos}

Caracterização da área de estudo - A floresta estudada localiza-se na fazenda São José $\left(22^{\circ} 21^{\prime}\right.$ S e $47^{\circ} 28^{\prime}$ W), que abrange uma porção do Município de Rio Claro e outra do Município de Araras - SP. O clima da região é caracterizado por duas estações bem definidas, sendo uma seca, de abril a setembro, e outra chuvosa, de outubro a março, e enquadrase no tipo "Cwa" de Köppen (Setzer 1967). Dados do período de 1994 a 2003, da Estação Meteorológica de Rio Claro, localizada a cerca de $8 \mathrm{~km}$ da área de estudo, apontam precipitação anual média de $1.456 \mathrm{~mm}$, sendo $1.182 \mathrm{~mm}$ na estação chuvosa e $274 \mathrm{~mm}$ na estação seca. No mesmo período, a temperatura média do mês mais frio (junho) foi de $18,1^{\circ} \mathrm{Ce}$ do mês mais quente (janeiro) foi de $25^{\circ} \mathrm{C}$.

A floresta paludosa localiza-se no interior de um remanescente de floresta estacional semidecídua de aproximadamente 230 hectares, que apresenta dossel de 7 a $15 \mathrm{~m}$ de altura, indivíduos emergentes de até $30 \mathrm{~m}$ e o segundo estrato inferior a $7 \mathrm{~m}$; o estrato herbáceo é representado por ervas e indivíduos jovens dos estratos superiores e as lianas são muito abundantes, principalmente nas bordas e clareiras naturais (Pagano et al. 1987, 1995, Udulutsch et al. 2004).

A floresta paludosa é representada por uma pequena mancha de vegetação, com aproximadamente oito hectares, que ocupa um trecho com declividade média de $10 \%$, entre as cotas de 630 e $650 \mathrm{~m}$. Nessa área, muitos canais naturais de drenagem escoam da porção mais elevada da topografia para as cotas mais baixas, formando uma rede de drenagem direcionada para o Ribeirão Claro. A presença de água superficial, ocasionando o encharcamento do solo, confere ao ambiente o aspecto geral conhecido como "brejo". Neste caso, a estratificação da vegetação não é evidente e o estrato herbáceo-subarbustivo, pouco conspícuo em função do escoamento superficial da água no solo, é representado por Costus spiralis (Jacq.) Roscoe, Blechnum brasiliense Desv. e Psychotria spp., entre outras espécies, além de indivíduos jovens das espécies dos estratos superiores.

Procedimento de campo e análise dos dados - Para caracterização do estrato arbustivo-arbóreo da floresta paludosa utilizou-se o método de parcelas (Müller-Dombois \& Ellenberg 1974). Foram alocadas 45 parcelas medindo $10 \mathrm{~m}$ $\times 10 \mathrm{~m}$, totalizando 0,45 ha de área amostrada, distribuídas em três blocos de 15 parcelas contíguas posicionados ao longo do desnível topográfico, visando abranger diferentes condições ambientais. Um primeiro bloco de amostragem foi delimitado na cota mais baixa da floresta paludosa, onde a água aflora e flui, temporariamente, em muitos canais de drenagem; o segundo bloco foi instalado na cota intermediária da topografia, onde a saturação hídrica do solo também é temporária; o último bloco ocupou a cota mais alta em que a floresta está situada, onde há afloramento permanente de água do lençol freático. Nos dois primeiros blocos, o período de saturação hídrica do solo, observado 
no decorrer do ano de 2003, foi de seis meses, visto que quase todos os canais de drenagem secaram, nesses trechos, durante os meses de maio a outubro.

Em cada parcela, foram amostrados os indivíduos com PAP (perímetro à altura do peito) maior ou igual a $15 \mathrm{~cm}$. Conforme a metodologia adotada por Ivanauskas et al. (1997) e Romagnolo \& Souza (2000), os indivíduos perfilhados abaixo de 1,3 m foram incluídos quando pelo menos uma das ramificações apresentou $\mathrm{PAP} \geq 15 \mathrm{~cm}$, sendo as demais ramificações utilizadas para o cálculo das áreas basais. Cada indivíduo foi numerado com plaqueta de alumínio, medido (PAP e altura) e identificado por meio de chaves de identificação, auxílio de especialistas e comparação com materiais do Herbário Rioclarense (HRCB), onde as exsicatas encontram-se depositadas. Foi adotado o sistema de classificação de Cronquist (1988) para a listagem dos táxons.

Como descritores fitossociológicos foram utilizados os valores relativos de dominância e freqüência, o índice de valor de importância (VI) (Matteucci \& Colma 1982), o índice de diversidade de Shannon \& Weaver $\left(\mathrm{H}^{\prime}\right)$, considerando a base logarítmica natural, e a eqüabilidade de Pielou (J) (Brower \& Zar 1984). Os descritores foram calculados pelo programa Fitopac (Shepherd 1994).

Os solos foram classificados no campo, de acordo com o Sistema Brasileiro de Classificação de Solos (Embrapa 1999). Com auxílio de um trado foram coletadas amostras, no centro de cada parcela, nas profundidades de $0-20 \mathrm{~cm}, 20-40 \mathrm{~cm}$, $40-60$ cm e $60-80$ cm. Após avaliação das principais variações quanto à coloração e textura nos perfis dos solos, foram determinados locais com características edáficas distintas, onde foram abertas trincheiras para a classificação dos solos. A camada superficial foi caracterizada por meio de análises químicas. Para tanto, foi coletada uma amostra composta por nove subamostras em cada parcela, a uma profundidade de 0 a $20 \mathrm{~cm}$. As análises foram realizadas no Laboratório de Análise Química de Solo e Planta, do Centro de Ciências Agrárias da UFSCar, Campus de Araras. Os valores de matéria orgânica (M.O.), pH, soma de bases (SB), capacidade de troca catiônica (CTC), saturação por bases (V\%) e saturação por Alumínio ( $\mathrm{m} \%)$ foram comparados entre os três blocos por análise de variância, seguida pelo teste de comparação de médias de Tukey (Zar 1996).

A similaridade florística entre a floresta paludosa da fazenda São José e outros sete fragmentos de floresta paludosa foi avaliada por análise hierárquica aglomerativa, utilizando-se o método de ligação UPGMA (Unweighted Pair Groups Method using Arithmetic Averages) e o índice de similaridade de Jaccard (Müller-Dombois \& Ellenberg 1974). A análise de agrupamento foi baseada nos dados de presença e ausência das espécies de cada fragmento. Nessa análise, foram eliminados os táxons com identificação apenas nos níveis de gênero e família, que representaram 11,5\% do total, e foram revistas as sinonímias. Das 149 espécies arbustivoarbóreas restantes, 104 espécies foram excluídas das análises por ocorrerem em apenas um fragmento, tendo em vista que espécies exclusivas não contribuem para a avaliação da similaridade florística entre áreas (Kent \& Coker 1999).

\section{Resultados}

Florística e estrutura da comunidade florestal - Foram amostrados 1.651 indivíduos vivos, pertencentes a 49 espécies e 30 famílias (tabela 1). A densidade total foi de $3.669 \pm 996$ indivíduos.ha $^{-1}$, enquanto a área basal total foi de $21,76 \mathrm{~m}^{2}$, equivalente a 48,35 $\pm 19,42 \mathrm{~m}^{2} \cdot \mathrm{ha}^{-1}$. A diversidade de espécies ( $\left.\mathrm{H}^{\prime}\right)$ foi de 2,10 nats.indivíduo ${ }^{-1}$ e o valor de equiabilidade $(\mathrm{J})$ foi de 0,54. Embora usado também em outros estudos, o critério para a amostragem de indivíduos perfilhados (com pelo menos uma das ramificações com $P A P \geq 15 \mathrm{~cm}$ ) pode gerar uma subestimativa de densidade e número de espécies, por excluir indivíduos de menores PAP, cujas ramificações somadas apresentem valor de área basal igual ou superior à de indivíduos com PAP $\geq 15 \mathrm{~cm}$.

Apesar da estratificação ser pouco evidente, Calophyllum brasiliense Cambess. e Talauma ovata A. St.-Hil. foram representadas por muitos indivíduos de grande porte, com altura entre 11 e $14 \mathrm{~m}$, destacando-se no dossel da floresta estudada e, juntamente com Cedrela odorata L., atingiram altura superior a $20 \mathrm{~m}$, sobressaindo-se como emergentes. Outras espécies como Euterpe edulis Mart., Dendropanax cuneatum Decne \& Planch. e Calyptranthes concinna DC. foram usualmente representadas por indivíduos de porte mais baixo, com altura entre seis e $10 \mathrm{~m}$.

Poucas espécies se destacaram na comunidade, tais como Euterpe edulis, Calophyllum brasiliense e Talauma ovata, que perfizeram $72 \%$ da densidade total e $58 \%$ do VI. A concentração de muitos indivíduos em poucas espécies caracteriza a estrutura comunitária da formação e resulta no baixo valor de eqüabilidade observado.

Assim como observado para as espécies, também ocorreu um grupo pequeno de famílias prevalentes sobre as demais, em função tanto do número de espécies quanto do valor de importância. As famílias Euphorbiaceae (oito espécies), Meliaceae (seis), Myrtaceae (quatro), Arecaceae (três), Clusiaceae e Mimosaceae (duas) foram representadas por mais de uma espécie. As quatro famílias com maiores VI foram Arecaceae (26,8\%), Clusiaceae (25,2\%), Magnoliaceae $(9,5 \%)$ e Meliaceae $(9,4 \%)$. Essas quatro famílias somaram $71 \%$ do valor total, sendo que Clusiaceae e 
Tabela 1. Espécies arbustivo-arbóreas ( $\mathrm{PAP} \geq 15 \mathrm{~cm}$ ) encontradas em 0,45 ha de floresta paludosa na fazenda São José, Rio Claro (SP), ordenadas pelo valor de importância (VI, em porcentagem), seus respectivos números de registro (HRCB), número de indivíduos (NI) e valores de dominância relativa (DoR) e frequiência relativa (FR). *Sem coleta de material reprodutivo.

Table 1. Arboreal and shruby species $(\mathrm{CBH} \geq 15 \mathrm{~cm})$ found on 0,45 ha of swamp forest located in São José farm, municipality of Rio Claro, SP, ranked by descending importance value (IV, in percentage), their register number in HRCB, number of individuals (NI) and values of relative dominance (DoR) and relative frequency (FR). *Reproductive material not collected.

\begin{tabular}{|c|c|c|c|c|c|c|}
\hline Famílias & Espécies & $\mathrm{HRCB}$ & NI & DoR & FR & VI \\
\hline Arecaceae & Euterpe edulis Mart. & * & 680 & 21,95 & 10,73 & 24,62 \\
\hline Clusiaceae & Calophyllum brasiliense Cambess. & 40136 & 389 & 39,81 & 10,24 & 24,54 \\
\hline Magnoliaceae & Talauma ovata A. St.-Hill. & 40137 & 126 & 9,98 & 9,02 & 8,88 \\
\hline Meliaceae & Cedrela odorata $\mathrm{L}$. & $*$ & 29 & 8,36 & 3,9 & 4,67 \\
\hline Araliaceae & Dendropanax cuneatum Decne \& Planch. & 40810 & 58 & 3,15 & 7,07 & 4,58 \\
\hline Burseraceae & Protium spruceanum (Benth.) Engl. & 40143 & 53 & 1,84 & 6,59 & 3,88 \\
\hline Myrtaceae & Calyptranthes concinna DC. & 40131 & 56 & 0,74 & 5,61 & 3,25 \\
\hline Meliaceae & Guarea kunthiana C. DC. & 40812 & 29 & 0,52 & 4,63 & 2,30 \\
\hline Arecaceae & Syagrus romanzoffiana (Cham.) Glassman & $*$ & 25 & 1,96 & 3,17 & 2,21 \\
\hline Meliaceae & Guarea macrophylla Vahl & 40826 & 24 & 0,36 & 4,39 & 2,07 \\
\hline Myrtaceae & Eugenia florida DC. & 40146 & 21 & 1,69 & 3,17 & 2,05 \\
\hline Meliaceae & Trichilia pallida $\mathrm{Sw}$. & 40821 & 22 & 0,36 & 3,66 & 1,78 \\
\hline Styracaceae & Styrax pohlii A. DC. & 40827 & 15 & 1,17 & 2,68 & 1,59 \\
\hline Moraceae & Ficus obtusiuscula (Miq.) Miq. & 40822 & 16 & 0,98 & 2,68 & 1,54 \\
\hline Anacardiaceae & Tapirira guianensis Aubl. & 40922 & 8 & 1,64 & 1,95 & 1,36 \\
\hline Mimosaceae & Inga striata Benth. & 40908 & 9 & 0,73 & 1,95 & 1,07 \\
\hline Icacinaceae & Citronella gongonha (Mart.) R.A. Howard & 40830 & 9 & 0,72 & 1,71 & 0,99 \\
\hline Bignoniaceae & Tabebuia umbellata (Sond.) Sandwith & $*$ & 6 & 0,95 & 1,22 & 0,84 \\
\hline Arecaceae & Geonoma brevispatha Barb. Rodr. & 40909 & 11 & 0,10 & 1,22 & 0,66 \\
\hline Euphorbiaceae & Alchornea glandulosa Poepp. & * & 5 & 0,32 & 1,22 & 0,61 \\
\hline Olacaceae & Ximenia americana $\mathrm{L}$. & 40148 & 5 & 0,29 & 1,22 & 0,60 \\
\hline Myrsinaceae & Ardisia ambigua Mart. & 40816 & 6 & 0,08 & 1,22 & 0,55 \\
\hline Cecropiaceae & Cecropia pachystachya Trecul & $*$ & 5 & 0,13 & 0,98 & 0,47 \\
\hline Myrtaceae & Myrcia laruotteana Cambess. & 40140 & 4 & 0,10 & 0,98 & 0,44 \\
\hline Tiliaceae & Luehea cf. divaricata Mart. & * & 4 & 0,27 & 0,73 & 0,41 \\
\hline Bombacaceae & Pseudobombax grandiflorum (Cav.) A. Robyns & $*$ & 2 & 0,30 & 0,49 & 0,30 \\
\hline Euphorbiaceae & Croton piptocalyx Müll. Arg. & 33723 & 2 & 0,22 & 0,48 & 0,27 \\
\hline Chloranthaceae & Hedyosmum brasiliense Mart. ex Miq. & 40926 & 3 & 0,03 & 0,49 & 0,23 \\
\hline Euphorbiaceae & Croton urucurana Baill. & 40135 & 2 & 0,09 & 0,49 & 0,23 \\
\hline Fabaceae & Andira sp. & * & 2 & 0,06 & 0,49 & 0,22 \\
\hline Meliaceae & Trichilia casaretti C. DC. & 40138 & 2 & 0,05 & 0,49 & 0,22 \\
\hline Lecythidaceae & Cariniana estrellensis (Raddi) Kuntze & * & 2 & 0,29 & 0,24 & 0,22 \\
\hline Caesalpiniaceae & Copaifera langsdorffii Desf. & 39206 & 2 & 0,05 & 0,49 & 0,22 \\
\hline Lacistemataceae & Lacistema hasslerianum Chodat & 38368 & 2 & 0,03 & 0,49 & 0,21 \\
\hline Meliaceae & Trichilia claussenii C. DC. & 40906 & 2 & 0,02 & 0,49 & 0,21 \\
\hline Euphorbiaceae & Croton floribundus Spreng. & 33407 & 1 & 0,22 & 0,24 & 0,18 \\
\hline Euphorbiaceae & Phyllanthus sp. & * & 1 & 0,12 & 0,24 & 0,14 \\
\hline Euphorbiaceae & Sebastiania sp. & * & 2 & 0,04 & 0,24 & 0,13 \\
\hline Clusiaceae & Clusia criuva Cambess. & $*$ & 1 & 0,05 & 0,24 & 0,12 \\
\hline Myrtaceae & Eugenia dodoneifolia Cambess. & 40147 & 1 & 0,04 & 0,24 & 0,12 \\
\hline Sapotaceae & Chrysophyllum gonocarpum (Mart. \& Eichler) Engl. & $*$ & 1 & 0,04 & 0,24 & 0,11 \\
\hline Euphorbiaceae & Pera obovata (Klotzch) Baill. & 40283 & 1 & 0,04 & 0,24 & 0,11 \\
\hline Euphorbiaceae & Savia dictyocarpa Müll. Arg. & $*$ & 1 & 0,03 & 0,24 & 0,11 \\
\hline Melastomataceae & Miconia ligustroides (DC.) Naudin & 40142 & 1 & 0,02 & 0,24 & 0,11 \\
\hline Flacourtiaceae & Xylosma tweediana (Clos) Eichler. & * & 1 & 0,02 & 0,24 & 0,11 \\
\hline Oleaceae & Cheinanthus sp. & 40139 & 1 & 0,02 & 0,24 & 0,11 \\
\hline Rubiaceae & Psychotria carthaginensis Jacq. & 40823 & 1 & 0,01 & 0,24 & 0,11 \\
\hline Mimosaceae & Inga marginata Willd. & 40132 & 1 & 0,01 & 0,24 & 0,10 \\
\hline Apocynaceae & Aspidosperma sp. & 40920 & 1 & 0,01 & 0,24 & 0,10 \\
\hline
\end{tabular}


Magnoliaceae destacaram-se pela presença de uma só espécie, Calophyllum brasiliense e Talauma ovata, respectivamente, principalmente em função do grande número de indivíduos.

Solo - Os solos amostrados na cota mais alta da floresta paludosa foram classificados como Neossolos Flúvicos Tb Distróficos gleicos, que correspondem a solos aluviais, que recobrem solos subsuperficiais (páleo Gleissolos) originados da Formação Tatuí (J.G. Rueda, comunicação pessoal). Nesse trecho, observa-se transporte e depósito de material da cota mais alta, externa ao fragmento, onde se encontra uma estrada e cultivo de cana-de-açúcar. Assim, a camada superficial do solo, com cerca de 50 a $60 \mathrm{~cm}$ e cor avermelhada, contrasta-se com o solo de subsuperfície. Embora sua CTC seja elevada (tabela 2), provavelmente em função da argila transportada, a saturação por bases (V\%) foi mais baixa em relação aos outros blocos $(F=17,32$, $P<10^{-3}$ ), conferindo menor fertilidade.

Nos blocos estabelecidos nas cotas intermediária e inferior observam-se Argissolos Acizentados Distróficos gleizados, formados por uma sequiência de sedimentação flúvio lacustre argilizada que evoluiu em clima sazonal quente. Sobre essa seqüência de Argissolos encontram-se Gleissolos Háplicos Ta Distróficos típicos, originados por depósitos mais atuais, em condições anaeróbicas (J.G. Rueda, dados não publicados). Esses solos, caracterizados pelo horizonte glei mineral, textura muito argilosa e cor cinzenta decorrente da presença de $\mathrm{Fe}$ reduzido, mostraram-se menos ácidos em relação ao bloco da cota mais alta, em função do $\mathrm{pH}$ mais elevado $(F=6,87, P=0,001)$ e da menor saturação por Alumínio $(\mathrm{m} \%)(F=18,49, P<$ $\left.10^{-3}\right)$.

Similaridade florística entre as florestas paludosas no interior do Estado de São Paulo - A classificação hierárquica aglomerativa indicou a formação de dois grupos no nível próximo de $25 \%$ de fusão (figura 1), além de um fragmento que se manteve isolado dos demais (Itatinga). Das florestas comparadas (tabela 3), as que obtiveram a maior similaridade florística foram os dois fragmentos estudados por Toniato et al. (1998) no Município de Campinas e, secundariamente, estes com o presente estudo.

Das 45 espécies utilizadas para os cálculos de similaridade florística entre as florestas, Calophyllum brasiliense, Cecropia pachystachya Trecul,

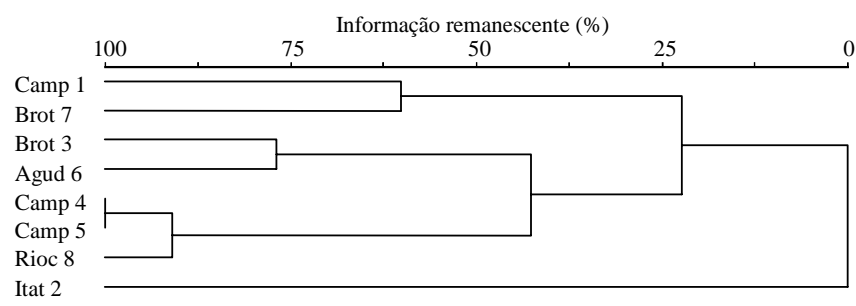

Figura 1. Dendograma gerado pela classificação hierárquica através da UPGMA, utilizando o coeficiente de similaridade de Jaccard, para estudos florísticos em florestas paludosas no interior do Estado de São Paulo (ver tabela 3).

Figure 1. Dendogram resulting from hierarchical classification using UPGMA and Jaccard's similarity coefficient, for floristic studies in the countryside of São Paulo state (see table 3).

Tabela 2. Variáveis químicas das amostras de solo (0-20 cm de profundidade) em três trechos (blocos B1, B2 e B3) de floresta paludosa na fazenda São José, Município de Rio Claro, SP. Os valores representam médias seguidas de desvios padrão. Médias seguidas por letras distintas indicam diferenças significativas entre si pelo teste de Tukey $(P<0,05)$. N = 15 parcelas para cada bloco.

Table 2. Chemical variables of soil samples (0-20 cm of depth) in three plots (B1, B2 and B3) of swamp forest located in São José farm, municipality of Rio Claro, SP. Values are mean followed by standard deviations. Means followed by different letters indicates significant differences in Tukey tests $(P<0,05) . \mathrm{N}=15$ subplots for each plot.

\begin{tabular}{|c|c|c|c|c|c|}
\hline \multirow[t]{2}{*}{ Variáveis químicas } & \multirow{2}{*}{$\begin{array}{c}\text { B1 } \\
\text { Gleissolos Háplicos } \\
\text { Ta Distróficos típicos }\end{array}$} & \multirow{2}{*}{$\begin{array}{c}\text { B2 } \\
\text { Gleissolos Háplicos } \\
\text { Ta Distróficos típicos }\end{array}$} & \multirow{2}{*}{$\begin{array}{c}\text { B3 } \\
\text { Neossolos Flúvicos } \\
\text { Tb Distróficos gleicos }\end{array}$} & \multicolumn{2}{|c|}{ ANOVA } \\
\hline & & & & $F$ & $P$ \\
\hline M.O. $\left(\mathrm{g} \cdot \mathrm{dm}^{-3}\right)$ & $39,53 \pm 10,8$ & $34,67 \pm 4,45$ & $35,27 \pm 5,36$ & 1,91 & 0,16 \\
\hline $\mathrm{pH} \mathrm{em} \mathrm{CaCI}_{2}$ & $4,32 \pm 0,35^{\mathrm{a}}$ & $4,24 \pm 0,16^{\mathrm{a}}$ & $3,97 \pm 0,16^{\mathrm{b}}$ & 6,87 & 0,001 \\
\hline $\mathrm{SB}\left(\mathrm{mmol}_{\mathrm{c}} \cdot \mathrm{dm}^{-3}\right)$ & $51,15 \pm 23^{a}$ & $40,98 \pm 5,98^{a b}$ & $35,23 \pm 9,08^{b}$ & 4,52 & 0,017 \\
\hline $\mathrm{CTC}\left(\mathrm{mmol}_{\mathrm{c}} \cdot \mathrm{dm}^{-3}\right)$ & $97,22 \pm 15,34^{\mathrm{b}}$ & $93,85 \pm 4,61^{\mathrm{b}}$ & $117,9 \pm 10,6^{\mathrm{a}}$ & 20,68 & $<10^{-3}$ \\
\hline $\mathrm{V}(\%)$ & $50,83 \pm 14,37^{\mathrm{a}}$ & $43,75 \pm 6,42^{\mathrm{a}}$ & $29,83 \pm 6,99^{b}$ & 17,32 & $<10^{-3}$ \\
\hline $\mathrm{m}(\%)$ & $10,27 \pm 8,04^{\mathrm{b}}$ & $11,63 \pm 6,19^{b}$ & $26,22 \pm 9,76^{\mathrm{a}}$ & 18,49 & $<10^{-3}$ \\
\hline
\end{tabular}


Tabela 3. Localização, dados climáticos e florísticos, critérios de inclusão dos indivíduos e área de amostragem dos remanescentes de florestas paludosas estudadas no interior do Estado de São Paulo. *Dados não fornecidos.

Table 3. Location, climatic and floristic data, sampling criteria, and size of area surveyed of the swamp forests in the countryside of São Paulo state. *Data not provided.

\begin{tabular}{|c|c|c|c|c|c|c|c|c|c|}
\hline Localidades & $\begin{array}{c}\text { Coordenadas } \\
\text { geográficas } \\
\text { (S, W })\end{array}$ & $\begin{array}{l}\text { Altitude } \\
\text { (m) }\end{array}$ & $\begin{array}{l}\text { Temperatura } \\
\text { média anual } \\
\left({ }^{\circ} \mathrm{C}\right)\end{array}$ & $\begin{array}{l}\text { Precipitação } \\
\text { média anual } \\
\qquad(\mathrm{mm})\end{array}$ & $\begin{array}{l}\mathrm{N}^{\circ} \mathrm{de} \\
\text { espécies }\end{array}$ & $\left(\mathrm{H}^{\prime}\right)$ & $\begin{array}{l}\text { Critério A } \\
\text { de inclusão }\end{array}$ & $\begin{array}{l}\text { Amostragem } \\
\text { (ha) }\end{array}$ & Referência \\
\hline Campinas (1) & $22^{\circ} 55^{\prime}, 47^{\circ} 05^{\prime}$ & 660 & 21,6 & 1371 & 33 & 2,45 & $\mathrm{DAP} \geq 5 \mathrm{~cm}$ & 0,87 & $\begin{array}{l}\text { Torres et al. } \\
\text { (1994) }\end{array}$ \\
\hline Itatinga (2) & $23^{\circ} 17^{\prime}, 48^{\circ} 38^{\prime}$ & 570 & 18 & $*$ & 39 & 2,75 & $\mathrm{PAP} \geq 15 \mathrm{~cm}$ & 1,00 & $\begin{array}{l}\text { Ivanauskas et al. } \\
\text { (1997) }\end{array}$ \\
\hline Brotas (3) & $22^{\circ} 15^{\prime}, 48^{\circ} 00^{\prime}$ & $*$ & 22 & 1428 & 33 & 2,52 & $\mathrm{PAP} \geq 15 \mathrm{~cm}$ & 0,20 & $\begin{array}{l}\text { Costa et al. } \\
\text { (1997) }\end{array}$ \\
\hline Campinas (4) & $22^{\circ} 49^{\prime}, 47^{\circ} 06^{\prime}$ & 600 & 21,6 & 1382 & 36 & 2,65 & $\mathrm{PAP} \geq 10 \mathrm{~cm}$ & 0,10 & $\begin{array}{l}\text { Toniato et al. } \\
\text { (1998) }\end{array}$ \\
\hline Campinas (5) & $22^{\circ} 49^{\prime}, 47^{\circ} 06^{\prime}$ & 600 & 21,6 & 1382 & 41 & 2,74 & $\mathrm{PAP} \geq 10 \mathrm{~cm}$ & 0,10 & $\begin{array}{l}\text { Toniato et al. } \\
\text { (1998) }\end{array}$ \\
\hline Agudos (6) & $22^{\circ} 30^{\prime}, 48^{\circ} 55^{\prime}$ & 550 & $*$ & 1464 & 38 & 2,60 & $\mathrm{PAP} \geq 15 \mathrm{~cm}$ & 0,22 & $\begin{array}{l}\text { Paschoal \& } \\
\text { Cavassan (1999) }\end{array}$ \\
\hline Brotas (7) & $22^{\circ} 16^{\prime}, 48^{\circ} 06^{\prime}$ & 470 & 22 & 1421 & 51 & 2,81 & $\mathrm{DAP} \geq 5 \mathrm{~cm}$ & 0,36 & $\begin{array}{l}\text { Marques et al. } \\
(2003)\end{array}$ \\
\hline Rio Claro (8) & $22^{\circ} 21^{\prime}, 47^{\circ} 28^{\prime}$ & 640 & 22,1 & 1456 & 49 & 2,10 & $\mathrm{PAP} \geq 15 \mathrm{~cm}$ & 0,45 & Este estudo \\
\hline
\end{tabular}

Dendropanax cuneatum, Protium spruceanum (Benth.) Engl., Talauma ovata, Tapirira guianensis Aubl. e Styrax pohlii A. DC. ocorreram em $100 \%$ das áreas analisadas. Além delas, Cedrela odorata, Citronella gongonha (Mart.) R.A. Howard, Guarea macrophylla Vahl e Pera obovata (Klotzch) Baill., também se mostraram muito freqüentes, por ocorrerem em pelo menos $75 \%$ das áreas.

\section{Discussão}

O número de espécies encontradas no presente estudo (49 espécies) foi inferior ao observado em Brotas (51 espécies), por Marques et al. (2003), porém superior aos demais valores encontrados em outras florestas paludosas do Estado de São Paulo, que variaram de 33 (Torres et al. 1994, Costa et al. 1997) a 41 espécies (Toniato et al. 1998). Esses valores devem ser comparados com ressalvas, pois são positivamente correlacionados com o tamanho das amostras (Magurram 1988, Melo et al. 2003), que foi muito variado nos diferentes levantamentos. O critério para a inclusão dos indivíduos também influencia o número de espécies amostradas. Em Campinas, Toniato et al. (1998) utilizaram um critério menos restritivo $(\mathrm{PAP} \geq 10 \mathrm{~cm})$ e, apesar da menor área amostrada
( 0,1 ha em cada remanescente), podem ter incluído espécies representadas por indivíduos com PAP menor que $15 \mathrm{~cm}$, valor mínimo usualmente utilizado nos demais estudos, que contribuíram com os valores encontrados (36 e 41 espécies).

Entretanto, os maiores valores encontrados em Brotas e Rio Claro podem estar correlacionados com a maior heterogeneidade espacial desses remanescentes. Segundo Marques et al. (2003), várias espécies foram registradas em Brotas devido às diferenças nos teores de umidade no solo, que se devem às variações topográficas. No presente estudo, variações quanto à saturação hídrica também são condicionadas pelas diferenças topográficas ao longo do declive e 26 espécies (53\%) foram verificadas apenas nos Gleissolos Háplicos, temporariamente inundados, enquanto três espécies $(6 \%)$ foram amostradas apenas nos Neossolos Flúvicos, permanentemente saturados. Diversos estudos têm demonstrado que variações florísticas em trechos contínuos nas zonas ciliares são geralmente relacionadas com variações no regime de inundação (Conner et al. 1981, Dunn \& Stearns 1987, Ferreira 2000, Ferreira \& Stohlgren 1999, Sampaio et al. 2000, Cattanio et al. 2002, Koponen et al. 2004). Por outro lado, condições homogêneas impostas pela água na 
camada superficial do solo podem reduzir a diferenciação de nichos (Duivenvoorden 1996) e, conseqüentemente, restringir o número de espécies.

A diversidade de espécies foi a mais baixa dentre os estudos em florestas paludosas do interior paulista, provavelmente em função da alta densidade de poucas espécies como Euterpe edulis, Calophyllum brasiliense e Talauma ovata. A alta concentração de indivíduos em poucas espécies mostrou-se mais acentuada na fazenda São José, visto que $41 \%$ dos indivíduos amostrados foram representados pelo palmiteiro E. edulis. Nos demais levantamentos, a espécie melhor representada ( $C$. brasiliense ou Protium spruceanum) apresentou valor de densidade relativa entre $19 \%$ e $25 \%$. A prevalência de E. edulis na área em questão constitui um diferencial dentre os estudos analisados. Nas demais áreas, a espécie não foi encontrada ou esteve representada por poucos indivíduos, muito provavelmente, em função de ações antrópicas (Paschoal \& Cavassan 1999), tendo em vista que essas formações seriam sítios propícios à ocorrência da espécie (Reis et al. 2000).

Tanto o número de espécies quanto a diversidade florística observados nas florestas paludosas mostraram-se mais baixos que os valores encontrados para outras formações florestais, como florestas ripárias e estacionais semidecíduas (Cavassan et al. 1984, Pagano \& Leitão Filho 1987, Durigan \& Leitão Filho 1995, Araújo et al. 1997, Rodrigues et al. 2003, Souza et al. 2003). Nessas formações, o número de espécies arbustivo-arbóreas amostradas foi muitas vezes igual ou superior a 100 e os valores de diversidade foram quase sempre superiores a 3, algumas vezes superando 4 nats.indivíduo ${ }^{-1}$. Os baixos valores de diversidade encontrados nas florestas paludosas são conseqüência não apenas do número restrito de espécies, mas também do pequeno número de espécies dominantes. A baixa riqueza específica e a alta densidade de indivíduos de algumas populações são atribuídas ao ambiente seletivo, decorrente da saturação hídrica do solo (Ferreira \& Stohlgren 1999), no qual poucas espécies tropicais como Calophyllum brasiliense (Marques \& Joly 2000a, b) e Talauma ovata (Lobo \& Joly 1995, 1996) possuem mecanismos adaptativos para se estabelecerem em condições de anoxia ou hipoxia.

Das espécies verificadas como muito freqüentes nas florestas paludosas, Calophyllum brasiliense e Protium almecega ocuparam sempre as primeiras posições em importância nas comunidades, enquanto Cedrela odorata, Dendropanax cuneatum, Talauma ovata, Tapirira guianensis e Styrax pohlii destacaram- se na maior parte dos estudos. Todas essas espécies constituem um importante grupo que define uma estrutura semelhante entre as florestas paludosas do interior paulista, caracterizada pela existência de poucas espécies que concentram muitos indivíduos na comunidade. A semelhança estrutural já foi destacada por Costa et al. (1997), em função da ocupação de porções bem definidas da paisagem, sujeitas a um longo período de saturação hídrica na superfície do solo ao longo do ano.

As famílias Euphorbiaceae, Lauraceae, Meliaceae, Moraceae e Myrtaceae apresentaram maior número de espécies na maioria dos estudos comparados. Quando considerados os valores de importância ou cobertura (VI e VC, respectivamente), as famílias Burseraceae, Clusiaceae, Magnoliaceae e Meliaceae, além de se mostrarem importantes na fazenda São José, destacaram-se também nos demais estudos que consideraram tais descritores (Torres et al. 1994, Ivanauskas et al. 1997, Toniato et al. 1998).

Apesar de um grupo característico de espécies e famílias amplamente dominantes em número de indivíduos, a composição florística das florestas paludosas mostrou-se muito variada, com particularidades definidas pelo altíssimo número de espécies exclusivas encontradas nos fragmentos estudados (70\% do total de espécies), ainda que esse fato possa resultar do baixo esforço amostral observado nos diferentes estudos. Apesar de pouco contribuírem para a estrutura dessas florestas, visto que suas densidades variaram de $1,4 \%$ (Toniato et al. 1998) a 22,7\% (Marques et al. 2003) dos indivíduos amostrados, essas espécies atribuem uma grande heterogeneidade à flora dessas formações e, no conjunto, promovem o aumento da diversidade.

A contribuição da vegetação do entorno para a flora das florestas paludosas poderia explicar essas particularidades florísticas (Costa et al. 1997, Ivanauskas et al. 1997, Toniato et al. 1998, Marques et al. 2003). Das 49 espécies amostradas na floresta paludosa estudada, foram observadas 20 espécies comuns com a floresta estacional semidecídua circundante, caracterizada por Pagano \& Leitão Filho (1987) e Pagano et al. (1995). As maiores similaridades observadas entre as florestas paludosas estudadas em Campinas (Toniato et al. 1998) e destas com a caracterizada no presente estudo, apóiam a hipótese da contribuição da vegetação do entorno, visto que, próximo aos dois fragmentos de Campinas, existe a Reserva Municipal de Santa Genebra que, como a fazenda São José, abriga um grande remanescente de floresta estacional semidecídua. 
É importante salientar que os estudos avaliados situam-se em uma porção muito restrita do estado, sujeita a regimes semelhantes de chuva e temperatura e, portanto, as variações climáticas não seriam determinantes para a diferenciação florística dessas áreas, como verificado para outras formações vegetacionais no estado (Salis et al. 1995, Scudeller et al. 2001, Durigan et al. 2003). Propriedades edáficas e estágio sucessional também podem influenciar esse tipo de análise (Torres et al. 1997), entretanto a escassez de dados relacionados a essas variáveis não possibilita essa avaliação. Por fim, o alto número de espécies exclusivas eliminadas na análise de similaridade restringe ainda mais as amostragens, cujos esforços são consideravelmente baixos.

Solos distróficos e ácidos, como encontrados sob a floresta paludosa estudada, também foram observados nas florestas paludosas de Campinas (Torres et al. 1994, Toniato et al. 1998) e Agudos (Paschoal \& Cavassan 1999). Entretanto, os solos da floresta paludosa da fazenda São José não se mostraram ricos em matéria orgânica como observado por Toniato et al. (1998) e Paschoal \& Cavassan (1999). A diferença nos teores de matéria orgânica pode estar associada às diferentes classes de solo observadas nessas florestas. Em comparação com as análises químicas da camada superficial dos solos da floresta semidecídua adjacente (A.G. Manzatto, comunicação pessoal), bem como de outras localidades (e.g. Araújo et al. 1997, Espírito Santo et al. 2002, Ruggiero et al. 2002, Rodrigues et al. 2003), os Gleissolos Háplicos identificados na floresta paludosa parecem não representar condições limitantes quanto às propriedades edáficas, uma vez que valores de mesma magnitude podem ser encontrados nas florestas estacionais semidecíduas. Entretanto, os Neossolos Flúvicos mostraram-se mais restritivos em relação à distribuição das espécies, provavelmente em função da maior acidez e da menor fertilidade ocasionadas pela saturação hídrica permanente na superfície do solo.

A floresta paludosa estudada apresenta-se como importante área para a ocorrência de E. edulis no interior paulista, uma vez que, de modo geral, as áreas que garantem a perpetuação desta espécie estão restritas principalmente às Unidades de Conservação. Outras espécies típicas de florestas paludosas, como Calophyllum brasiliense, Cedrela odorata, Protium spruceanum e Talauma ovata, têm ocorrência quase restrita a esse tipo de ambiente, onde são verificadas com grande densidade de indivíduos. Embora encontradas eventualmente em florestas mais secas, não são bem representadas. Além de favorecer a ocorrência das principais populações associadas a solos hidromórficos, cada fragmento de floresta paludosa apresenta peculiaridades florísticas que, somadas, abrigam um grande número de espécies. Portanto, é necessária a conservação do fragmento estudado na fazenda São José e do maior número possível de remanescentes de florestas paludosas situadas no interior paulista, independentemente do tamanho da área que ocupam.

Agradecimentos - Agradecemos Rodrigo A.S. Pereira, Ricardo R. Rodrigues, Maria T.Z. Toniato, Reinaldo Monteiro e assessores anônimos pelas sugestões no manuscrito; Vinícius A.O. Dittrich e R. Monteiro pela revisão de inglês; Luís C. Bernacci (Myrsinaceae), Rosely B. Torres (Flacourtiaceae), Carolyn Proença e Lúcia H. Soares-Silva (Myrtaceae) pela identificação taxonômica; Jairo G. Rueda pela classificação dos solos e José C. Casagrande pelas análises de solo; Fernando R. Siqueira, Ângelo G. Manzatto, Daniel S. Huet, Júlio M. Kojima, Leandro J. Fonseca, Maurício N. Godoi, Robson L. Capretz e Eduardo G.B. Prata pela ajuda nos trabalhos de campo; família Paula Machado proprietária da Fazenda São José. O primeiro autor foi financiado pela Capes (bolsa de mestrado).

\section{Referências bibliográficas}

ARAÚJO, G.M., GUIMARÃES, A.J.M. \& NAKAJIMA, J.N. 1997. Fitossociologia de um remanescente de mata mesófila semidecídua urbana, Bosque John Kennedy, Araguari, MG, Brasil. Revista Brasileira de Botânica 20:67-77.

BROWER, J.E. \& ZAR, J.H. 1984. Field and laboratory methods for general ecology. Wm. C. Brown, Dubuque.

CATTANIO, J.H., ANDERSON, A.B. \& CARVALHO, M.S. 2002. Floristic composition and topographic variation in a tidal floodplain forest in the Amazon estuary. Revista Brasileira de Botânica 25:419-430.

CAVASSAN, O., CÉSAR, O. \& MARTINS, F.R. 1984. Fitossociologia da vegetação arbórea da Reserva Estadual de Bauru, estado de São Paulo. Revista Brasileira de Botânica 7:91-106.

CONNER, W.H., GOSSELINK, J.G. \& PARRONDO, R.T. 1981. Comparison of the vegetation of three Louisiana swamp sites with different flooding regimes. American Journal of Botany 68:320-331.

COSTA, F.R.C., SCHLITTLER, F.H.M., CÉSAR, O. \& MONTEIRO, R. 1997. Aspectos florísticos e fitossociológicos de um remanescente de brejo no município de Brotas, SP. Arquivos de Biologia e Tecnologia 40:263-270.

CRONQUIST, A. 1988. The evolution and classification of flowering plants. New York Botanical Garden, New York.

DUIVENVOORDEN, J.F. 1996. Patterns of tree species richness in rain forests of the middle Caquetá area, Colombia, NW Amazonia. Biotropica 28:142-158. 
DUNN, C.P. \& STEARNS, F. 1987. A comparison of vegetation and soils in floodplain and basin forested wetlands of southeastern Wisconsin. American Midland Naturalist 118:375-384.

DURIGAN, G. \& LEITÃO FILHO, H.F. 1995. Florística e fitossociologia de matas ciliares do Oeste paulista. Revista do Instituto Florestal 7:197-239.

DURIGAN, G., SIQUEIRA, M.F., FRANCO, G.A.D.C., BRIDGEWATER, S. \& RATTER, J.A. 2003. The vegetation of priority areas for cerrado conservation in São Paulo State, Brazil. Edinburgh Journal of Botany 60:217-241.

EMBRAPA 1999. Sistema brasileiro de classificação de solos. Empresa Brasileira de Pesquisa Agropecuária, Centro Nacional de Pesquisa de Solos, Rio de Janeiro.

ESPÍRITO SANTO, F.D.B, OLIVEIRA FILHO, A.T., MACHADO, E.L.M., SOUZA, J.S., FONTES, M.A.L. \& MARQUES, J.J.G.S.M. 2002. Variações ambientais e a distribuição de espécies arbóreas em um remanescente de floresta estacional semidecídua montana no campus da Universidade Federal de Lavras, MG. Acta Botanica Brasilica 16:331-356.

FERREIRA, L.V. 2000. Effects of flooding duration on species richness, floristic composition and forest structure in river margin habitat in Amazonian blackwater floodplain forests: implications for future design of protected areas. Biodiversity and Conservation 9:1-14.

FERREIRA, L.V. \& STOHLGREN, T.J. 1999. Effects of river level fluctuation on plant species richness, diversity, and distribution in a floodplain forest in Central Amazonia. Oecologia 120:582-587.

IVANAUSKAS, N.M., RODRIGUES, R.R. \& NAVE, A.G. 1997. Aspectos ecológicos de uma mata de brejo em Itatinga, SP: florística, fitossociologia e seletividade de espécies. Revista Brasileira de Botânica 20:139-153.

KENT, M. \& COKER, P. 1999. Vegetation description and analysis: a practical approach. J. Wiley, London.

KOPONEN, P., NYGREN, P., SABATIER, D., ROUSTEAU, A. \& SAUR, E. 2004. Tree species diversity and forest structure in relation to microtopography in a tropical freshwater swamp forest in French Guiana. Plant Ecology 173:17-32.

LEITÃO FILHO, H.F. 1982. Aspectos taxonômicos das florestas do estado de São Paulo. In Anais do I Congresso nacional sobre essências nativas, Campos do Jordão. Silvicultura em São Paulo, São Paulo, v.1, p.197-206.

LOBO, P.C. \& JOLY, C.A. 1995. Mecanismos de tolerância à inundação de plantas de Talauma ovata St.-Hil. (Magnoliaceae), uma espécie típica de matas de brejo. Revista Brasileira de Botânica 18:177-183.

LOBO, P.C. \& JOLY, C.A. 1996. Ecofisiologia da germinação de sementes de Talauma ovata St. Hil. (Magnoliaceae), uma espécie típica de matas de brejo. Revista Brasileira de Botânica 19:35-40.

MAGURRAM, A.E. 1988. Ecological diversity and its measurement. Princeton University, Princeton.
MARQUES, M.C.M. \& JOLY, C.A. 2000a. Estrutura e dinâmica de uma população de Calophyllum brasiliense Camb. em floresta higrófila do sudeste do Brasil. Revista Brasileira de Botânica 23:107-112.

MARQUES, M.C.M. \& JOLY, C.A. 2000b. Germinação e crescimento de Calophyllum brasiliense (Clusiaceae), uma espécie típica de florestas inundadas. Acta Botanica Brasilica 14:113-120.

MARQUES, M.C.M., SILVA, S.M. \& SALINO, A. 2003. Florística e estrutura do componente arbustivo-arbóreo de uma floresta higrófila da bacia do rio Jacaré-Pepira, SP, Brasil. Acta Botanica Brasilica 17:495-506.

MATTEUCCI, S.D. \& COLMA, A. 1982. Metodologia para el estudio de la vegetacion. Secretaria General de la Organización de los Estados Americanos, Washington.

MELO, A.S., PEREIRA, R.A.S., SANTOS, A.J., SHEPHERD, G.J., MACHADO, G., MEDEIROS, H.F. \& SAWAYA, R.J. 2003. Comparing species richness among assemblages using sample units: why not use extrapolation methods to standardize different sample sizes? Oikos 101:398-410.

MÜLLER-DOMBOIS, D. \& ELLENBERG, H. 1974. Aims and methods of vegetation ecology. Wiley and Sons, New York.

PAGANO, S.N. \& LEITÃO FILHO, H.F. 1987. Composição florística do estrato arbóreo de mata mesófila semidecídua no município de Rio Claro (estado de São Paulo). Revista Brasileira de Botânica 10:34-47.

PAGANO, S.N., LEITÃOFILHO, H.F. \& SHEPHERD, G.J. 1987. Estudo fitossociológico em mata mesófila semidecídua no município de Rio Claro (estado de São Paulo). Revista Brasileira de Botânica 10:49-61.

PAGANO, S.N., LEITÃO FILHO, H.F. \& CAVASSAN, O. 1995. Variação temporal da composição florística e estrutura fitossociológica de uma floresta mesófila semidecídua Rio Claro - estado de São Paulo. Revista Brasileira de Biologia 55:241-258.

PASCHOAL, M.E.S. \& CAVASSAN, O. 1999. A flora arbórea da mata de brejo do ribeirão do Pelintra, Agudos, SP. Naturalia 24:171-191.

REIS, M.S., GUERRA, M.P., NODARI, R.O., RIBEIRO, R.J. \& REIS, A. 2000. Distribuição geográfica e situação atual das populações na área de ocorrência de Euterpe edulis Martius. Sellowia 49-52:324-335.

RODRIGUES, L.A., CARVALHO, D.A., OLIVEIRAFILHO,A.T, BOTREL, R.T. \& SILVA, E.A. 2003. Florística e estrutura da comunidade arbórea de um fragmento florestal em Luminárias, MG. Acta Botanica Brasilica 17:71-87.

ROMAGNOLO, M.B. \& SOUZA, M.C. 2000. Análise florística e estrutural de florestas ripárias do alto rio Paraná, Taquaruçu, MS. Acta Botanica Brasilica 14:163-174.

RUGGIERO, P.G.C., BATALHA, M.A., PIVELLO, V.R. \& MEIRELLES, S.T. 2002. Soil vegetation relationships in cerrado (Brazilian savanna) and semideciduous forest, Southeastern Brazil. Plant Ecology 160:1-16.

SALIS, S.M., SHEPHERD, J.G. \& JOLY, C.A. 1995. Floristic comparison of mesophytic semideciduous forests of the interior of the state of São Paulo, southeast Brazil. Vegetatio 119:155-164. 
SAMPAIO, A.B., WALTER, B.M.T. \& FELFILI, J.M. 2000. Diversidade e distribuição de espécies arbóreas em duas matas de galeria na microbacia do Riacho Fundo, Distrito Federal. Acta Botanica Brasilica 14:197-214.

SCUDELLER, V.V., MARTINS, F.R. \& SHEPHERD, GJ. 2001. Distribution and abundance of arboreal species in the atlantic ombrophilous dense forest in Southeastern Brazil. Plant Ecology 152:185-199.

SETZER, J. 1967. Atlas climático e ecológico do Estado de São Paulo. Comissão interestadual da Bacia ParanáUruguai, São Paulo.

SHEPHERD, G.J. 1994. Fitopac. Manual do usuário. Universidade Estadual de Campinas, Campinas.

SOUZA, J.S., ESPÍRITO SANTO, F.D.B., FONTES, M.A.L., OLIVEIRAFILHO, A.T. \& BOTEZELLI, L. 2003. Análise das variações florísticas e estruturais da comunidade arbórea de um fragmento de floresta semidecídua às margens do rio Capivari, Lavras - MG. Revista Árvore 27:185-206.
TONIATO, M.T.Z., LEITÃOFILHO, H.F. \& RODRIGUES, R.R. 1998. Fitossociologia de um remanescente de floresta higrófila (mata de brejo) em Campinas, SP. Revista Brasileira de Botânica 21:197-210.

TORRES, R.B, MATTHES, L.A.F. \& RODRIGUES, R.R. 1994. Florística e estrutura do componente arbóreo de mata de brejo em Campinas, SP. Revista Brasileira de Botânica 17:189-194.

TORRES, R.B, MARTINS, F.R. \& KINOSHITA, L.S. 1997. Climate, soil and tree flora relationships in the state of São Paulo, southeastern Brazil. Revista Brasileira de Botânica 20:41-49.

UDULUTSCH, R.G., ASSIS, M.A. \& PICCHI, D.G. 2004. Florística de trepadeiras numa floresta estacional semidecídua, Rio Claro - Araras, estado de São Paulo, Brasil. Revista Brasileira de Botânica 27:125-134.

ZAR, J.H. 1996. Bioestatistical analysis. Prentice-Hall, New Jersey. 